\section{The effect of duration of item exposure on recall in a short-term memory paradigm*}

\author{
LAURENCE MILLER \\ Western Washington State College, Bellingham, Wash. 98225
}

Ss were tested for recall of six consonant trigrams at retention intervals of 0,3 , and $18 \mathrm{sec}$ with a 2,000 , 500-, or $200-\mathrm{msec}$ duration of item exposure. As duration was reduced, retention at 3 - and 18 -sec within- and between-exposure durations declined for all items, and the interaction between length of retention interval and number of items was significantly reduced for the initial and middle items. The results were interpreted in terms of increased proactive interference as item exposure was reduced.

The procedure for studying short-term memory (STM), as contrasted to long-term memory (LTM), involves presenting retention intervals, of relatively short duration and allowing only a brief exposure of the item before the interval begins. In their classic study, Peterson \& Peterson (1959) read three letters to their Ss and then examined retention of those trigrams over intervals of $3-18 \mathrm{sec}$. The items were presented only briefly, since longer exposure would presumably allow Ss to rehearse, that is, to practice the item or encode it by means of a mnemonic aid, thus possibly transferring the item from STM to LTM (Adams, 1967).

Several STM studies have shown that if S is allowed to rehearse the item before the retention interval is initiated, recall of that item is significantly increased. Peterson \& Peterson (1959) allowed their Ss 0, 1 , or $3 \mathrm{sec}$ of vocal rehearsal after exposure of the item and found higher recall with longer rehearsal times. Hellyer (1962) found that eight overt repetitions, at a rate of one repetition per second, before the retention interval, maintained retention at or above $80 \%$ for intervals of $3-27 \mathrm{sec}$. Sanders (1961) and Pollack (1963) obtained similar results with covert practice. Keppel \& Underwood (1962) found that when their items were exposed for $2 \mathrm{sec}$, retention was higher than when the items were read to Ss, as Peterson \& Peterson (1959) did. Presumably, the 2-sec exposure allowed substantially more practice to occur.

The present experiment examined retention as it is influenced by the duration of item exposure. By varying exposure duration, the amount of possible rehearsal time afforded $S$ can be directly controlled. Three durations of exposure were studied: (1) $2,000 \mathrm{msec}(2.0 \mathrm{sec})-$ the exposure duration used by Keppel \& Underwood (1962). A duration of this length should permit considerable rehearsal);

*The author would like to thank Lynne Chavelle for her help in running this experiment.
(2) $500 \mathrm{msec}(0.5 \mathrm{sec})-$ this exposure duration should minimize rehearsal; (3) $200 \mathrm{msec}(0.2 \mathrm{sec})$-the reaction time of the eye to stimuli is about $200 \mathrm{msec}$ (Neisser, 1967). No repetition of the item should occur at this duration.

\section{PROCEDURE}

The Ss were 288 undergraduate introductory psychology students. The apparatus consisted of a scientific prototype two-channel tachistoscope, Model 800-F, and a hand "cricket." The letter trigrams were typed on $4 \times 5 \mathrm{in}$. white cards. The letters were capitalized and stood 0.25 in. high.

Five separate groups of Ss were run. Three groups of 72 Ss followed the procedure used by Keppel \& Underwood (1962). This procedure is valuable because it allows examination of retention as a function of both different retention intervals and number of prior items which have been presented. Each group was run under one of the three exposure durations. Each $\mathrm{S}$ was presented six separate items and intervals of 3 and $18 \mathrm{sec}$ were examined. The six consonant trigrams used by Keppel and Underwood were utilized here. Ss were given both 3 - and 18 -sec retention intervals. Half of $\mathrm{Ss}$ at each exposure duration were given the intervals in the order of 3-18-3-18-3.18, and the other group in the reverse order. Three orders of item presentation were counterbalanced across groups. This procedure allowed measures of retention after $0,1,2,3,4$, and 5 previous items for 3 and $18 \mathrm{sec}$, with an exposure duration of $2,000,500$, or $200 \mathrm{msec}$.

The Ss were instructed to sit facing the tachistoscope and were told to always look into the viewer throughout the experiment. A single click of the cricket was a signal that letters would appear $2 \mathrm{sec}$ later in the visual field of the tachistoscope. With Ss given the 3- and 18-sec retention intervals, as soon as the letters left the screen, E read a three-digit number, from which $S s$ counted backwards by three as fast as they could, in order to minimize rehearsal during the interval. Ss were not allowed to pause while counting and averaged about 1.5 to 2 counts per second. As soon as Ss heard the cricket click twice, they stopped counting and tried to recall the letters. They were allowed $4 \mathrm{sec}$ for recall. Recall was counted as correct only if the three letters were repeated in the order in which they appeared. A 15 -sec intertrial interval intervened between the presentation of successive items.

Because the 500- and 200-msec exposure durations are relatively brief, it is possible that some errors in recall could be due to Ss' failure to perceive the items correctly rather than due to the effect of number of prior items and retention interval. In order simply to determine how clearly the items could be perceived at these briefer durations, an immediate recall control group of $36 \mathrm{Ss}$ was also run with the 500 and $200-\mathrm{msec}$ exposure durations. For each of these two groups the retention interval was 0 sec for each item; that is, the cricket clicked twice as soon as each item went off the tachistoscope screen.

\section{RESULTS AND DISCUSSION}

Percent correct recall for each item at each exposure duration and retention interval is shown in Fig. 1. The pattern of retention for the six items with the $18-\mathrm{sec}$ interval is very similar for the three exposure durations. Retention was highest for Item 1 and steadily declined across subsequent items. For the 2,000 and 500-msec exposure durations, Item 1 recall was significantly better than recall for Items $2-6$, using one-tailed $\mathrm{z}$-score tests with a $5 \%$ level of significance. For the $200-\mathrm{msec}$ duration, the decline in recall was less steep because of the already low recall of Item 1. Recall of Item 1 was significantly better than recall of Items 4-6.

Keppel \& Underwood (1962) explained this decline in retention across items for the 18-sec interval as due to an interaction between a facilitating learning-to-learn effect with successive exposure to items and an increase in the number of interfering associations from prior items. The 18-sec interval permits' recovery of sufficient proactive interference (PI) from prior items to outweigh the learning effect, and retention falls across items.

Although the pattern of retention with the 18-sec interval is similar for each of the exposure durations, as duration is reduced, retention also declines. Recall with a $2,000-\mathrm{msec}$ exposure at $18 \mathrm{sec}$ was higher than recall with a $500-\mathrm{msec}$ exposure at $18 \mathrm{sec}$ for all six items. These differences were significant for Items $1-4$ and for Item 6. Apparently, the inhibiting influence of PI on recall became even stronger as exposure duration was reduced. It should be noted that the difference in 

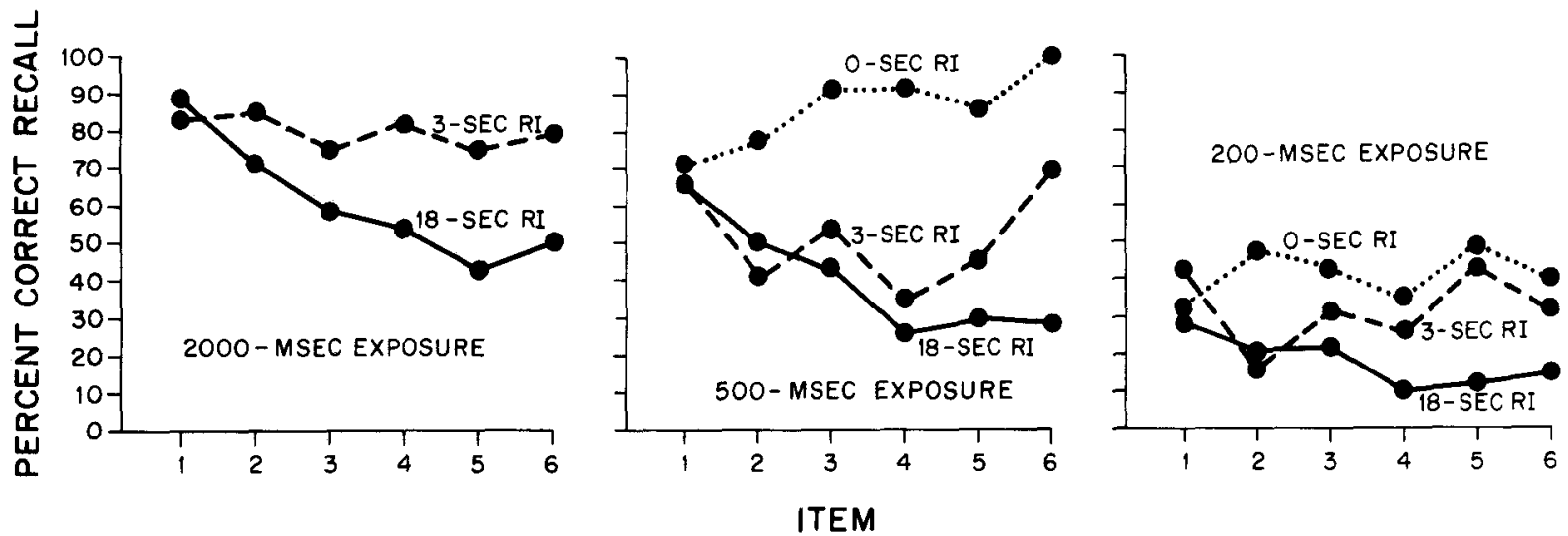

Fig. 1. Percent correct recall for each retention interval (RI) at each duration of exposure.

retention for Item 1 was probably the result of not perceiving the item correctly at the 500-msec exposure. Even with immediate recall ( 0 -sec retention interval), recall for Item 1 was nearly the same as recall for the first item with $18-\mathrm{sec}$ retention interval. However, a learning effect due to successive exposures at the 0 -sec interval is evident with Item 2 , as retention began to rise steadily.

Retention with 500-msec exposure at the 18-sec retention interval was, in turn, superior to recall with $200-\mathrm{msec}$ exposure and 18 -sec interval. However, the results of the 0-sec-interval group at 200-msec exposure indicate that only about one-third to one-half of the Ss, depending upon the item, could perceive that item correctly. A large number of Ss, for example, reported that they could perceive only either a blur or blank screen. Because of this high proportion of misperceptions, it is difficult to compare the 200 -msec group with any of the other exposure groups.

In contrast to recall at $18 \mathrm{sec}$ with 2,000 -msec exposure, recall at $3 \mathrm{sec}$ was nearly constant across the six items. No item's recall was significantly different from the recall of any other item. According to Keppel \& Underwood (1962), with a short retention interval proactive interference does not recover sufficiently, so that the practice effect and PI balance and retention remains constant across items.

However, at $500-\mathrm{msec}$ exposure, retention at $3 \mathrm{sec}$ declined beyond Item 1 and only Item 6 approached a comparable level of recall. Recall for Item 1 was significantly higher than was the recall of Items 2, 4, and 5. Recall at 200-msec exposure at $3 \mathrm{sec}$ exhibited a similar pattern, with recall of the initial and middle items depressed and not rising again until the terminal items. Recall for Item 1 was significantly better than recall for Items 2 and 3 . These results suggest that with reduced exposure duration, recall suffered a decrement due to PI and that the learning effect was most effectively able to counteract this PI at the terminal items.

Like recall with the $18-\sec$ interval, recall with the $3-\mathrm{sec}$ interval fell at each item as exposure duration was reduced, demonstrating the heightened effect of PI at shorter exposure durations. Recall for the $3-\mathrm{sec}$ interval was significantly better at $2,000-\mathrm{msec}$ exposure than at $500-\mathrm{msec}$ exposure for Items 1-5. Again, however, the difference with Item 1 was probably due to misperception of the item at $500 \mathrm{msec}$. Recall at $3 \mathrm{sec}$ with $200-\mathrm{msec}$ exposure was lower than recall at $3 \mathrm{sec}$ with 500-msec exposure, but because of the already low level of recall at $200 \mathrm{msec}$, it is difficult to directly compare the two intervals.

With a 2,000-msec exposure the interaction between number of items and length of retention interval is apparent. As the number of items is increased, the difference in recall between 3 and $18 \mathrm{sec}$ becomes greater. Items $2-6$ differed significantly between 3 and $18 \mathrm{sec}$. However, with 500- and 200-msec exposures, this interaction was reduced significantly with the initial and middle items and was most apparent at the terminal items. Recall was higher at $3 \mathrm{sec}$ than at $18 \mathrm{sec}$ beyond Item 2 ; however, this difference was significant only at Item 6 with $500 \mathrm{msec}$ exposure and with Items 4-6 with 200-msec exposure.

In conclusion, these results suggest that the duration of exposure of an item plays a crucial role in recall of that item. The following results were obtained when exposure duration was reduced: (1) Retention at both short (3-sec) and longer $(18-\mathrm{sec})$ retention intervals declined for all items; (2) the practice effect at the short interval was not clearly manifested until the terminal items; (3) retention at the longer interval continued to decline across the six items; (4) the interaction between length of retention interval and number of items was reduced at the initial and middle items and was significant only at the terminal items. These results were attributed to the increased potency of PI from prior items, particularly at the short interval.

If a long duration of exposure permits substantial covert rehearsal of the item before the retention interval begins, this rehearsal is sufficient to minimize forgetting from PI at short retention intervals and to retard the rate of forgetting at longer retention intervals. Ss reported that they were able to rehearse the item before the retention interval began with a 2,000-msec exposure. However, if the duration of item exposure is short enough to preclude rehearsal, retention, even at short intervals, is significantly reduced by the now preeminent PI. Ss stated that they were unable to rehearse the item when it was exposed for only 500-msec. Only with immediate recall at the 500-msec exposure did retention remain at a high constant level. When rehearsal and its possible attendant LTM effects are minimized and one approaches a more nearly pure STM paradigm, retention is found to be highly susceptible to PI at both long and short retention intervals.

\section{REFERENCES}

ADAMS, J. A. Human memory. New York: McGraw-Hill, 1967.

HELLYER, S. Supplementary report: I requency of stimulus presentation and short-term decrement in recall. Journal of Experimental Psychology, 1962, 64, 650.

KEPPEL, G., \& UNDERWOOD, B. J. Proactive inhibition in short-term retention of single items. Journal of Verbal Learning \& Verbal Behavior, 1962, 1, 153-161.

NEISSER, U. Cognitive psychology. New York: Appleton-Century-Crofts, 1967.

PETERSON, L., \& PETERSON, M. J. Short-term retention of individual verbal items. Journal of Experimental Psychology, 1959, 58, 193-198.

POLLACK, I, Interference, rehearsal, and short-term retention of digits. Canadian Journal of Psychology, 1963, 17, 380-392.

SANDERS, A. F. Rehearsal and recall in immediate memory. Ergonomics, 1961, 4, 29.34. 